\title{
Tribological and Mechanical Behavior of Graphite Composites of Polytetrafluoroethylene (PTFE) Irradiated by the Electron Beam
}

\author{
Adrian Barylski ${ }^{1}{ }^{\circledR}$, Andrzej S. Swinarew ${ }^{1,2}{ }^{(}$, Krzysztof Aniołek $^{1}{ }^{\circledR}$, Stawomir Kaptacz ${ }^{1}{ }^{(D}$,

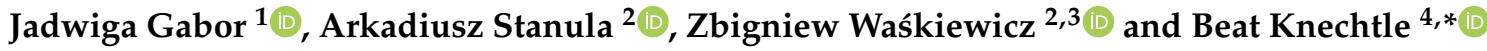 \\ 1 Faculty of Science and Technology, Institute of Materials Engineering, University of Silesia in Katowice, \\ 75 Pułku Piechoty 1A, 41-500 Chorzów, Poland; adrian.barylski@us.edu.pl (A.B.); \\ andrzej.swinarew@us.edu.pl (A.S.S.); krzysztof.aniolek@us.edu.pl (K.A.); \\ slawomir.kaptacz@us.edu.pl (S.K.); jadwiga.gabor@us.edu.pl (J.G.) \\ 2 Institute of Sport Science, The Jerzy Kukuczka Academy of Physical Education, Mikołowska 72A, \\ 40-065 Katowice, Poland; a.stanula@awf.katowice.pl (A.S.); z.waskiewicz@awf.katowice.pl (Z.W.) \\ 3 Department of Sports Medicine and Medical Rehabilitation, Sechenov University, 119991 Moscow, Russia \\ 4 Institute of Primary Care, University of Zurich, 8091 Zurich, Switzerland \\ * Correspondence: beat.knechtle@hispeed.ch
}

Received: 30 June 2020; Accepted: 25 July 2020; Published: 28 July 2020

\begin{abstract}
This research investigated the effect of irradiation with an electron beam energy of $10 \mathrm{MeV}$ in doses of 26-156 kGy on polytetrafluoroethylene (PTFE) with a $15 \%$ and $20 \%$ graphite additive. The research has shown that mechanical (compression strength, hardness, and Young's modulus) and sclerometric (coefficient of wear micromechanism and coefficient of resistance to wear) properties improve and tribological wear decreases as graphite content increases. Electron beam irradiation increases the degree of crystallinity of both materials to a similar extent. However significant differences in the improvement of all examined properties have been demonstrated for PTFE with higher $(20 \%)$ graphite content subjected to the electron beam irradiation. This polymer is characterized by higher hardness and Young's modulus, reduced susceptibility to permanent deformation, higher elasticity, compression strength, and above all, a nearly $30 \%$ reduction in tribological wear compared to PTFE with a 15\% graphite additive. The most advantageous properties can be obtained for both of the examined composites after absorbing a dose of $104 \mathrm{kGy}$. The obtained results hold promise for the improvement of the operational life of friction couples which do not require lubrication, used for example in air compressors and engines, and for the possibility of application of these modified polymers. In particular PTFE with 20\% graphite content, in the nuclear and space industry.
\end{abstract}

Keywords: PTFE; graphite; electron beam irradiation; differential scanning calorimetry (DSC); mechanical properties; wear

\section{Introduction}

Polytetrafluoroethylene (PTFE) has favorable properties like high chemical and biological tolerance, thermal stability, as well as its excellent dielectric, antifriction, and antiadhesive properties, polytetrafluoroethylene (PTFE) is a preferable material for the manufacture of articles in different industries and engineering [1-6]. For tribological applications, PTFE is also an expedient polymer material that is widely available. The structure of PTFE molecules causes transfer of material thin film onto the surface during friction improving value of the friction coefficient [7-9]. It is a known fact that during tribological interaction pure PTFE without technological defects resulting from the 
manufacturing process like polymer plates and nodules (few tenths of a millimeter) is featured by a very high degree of wear [7]. There are several ways to improve the wear rate, for example by adding different types of fillers to the material and also by using electron-beam or gamma-beam irradiation [9-12]. For example, graphite additive has a positive effect on parameters such as friction coefficient, stiffness, and mechanical strength, and it also slightly improves abrasion wear values [7].

First attempts to use ionizing radiation to modify polytetrafluoroethylene were already made in the sixties. $[13,14]$. At first, these attempts were ineffective because even with very low doses they caused deterioration of physical and mechanical properties and because of that PTFE was classified as one of polymers with the highest sensitivity to irradiation $[15,16]$.

Subsequent research has shown, however, that irradiation improves a number of mechanical properties such as abrasion resistance, creep resistance, adhesive strength, abrasion strength, and also have positive influence on radiation resistance, processability, possibility for modification and enables control over properties of the obtained material [17]. An increase in resistance to abrasive wear of irradiated at ambient temperature PTFE was observed [18-20]. The initial failures were caused by the fact that in PTFE at room temperature the predominant phenomenon is the breakage of the main polymer chain, and the cross-linking phenomenon occurs only at a temperature similar to the melting point of PTFE [17-20]. Tabata et al. proved that the cross-linking of PTFE with a linear structure may occur only in type $Y$ because the steric hindrance of geometric conformation prevents the formation of $\mathrm{H}$ type cross-linking [17]. The detailed mechanism that occur during the cross-linking of polytetrafluoroethylene have been described in detail in Khatipov's paper [21]. Khatipov's team also investigated friction and abrasion properties of pure PTFE and PTFE irradiated with doses up to $350 \mathrm{kGy}$. It has been demonstrated that the friction coefficient of specimens irradiated at a high temperature was close to the value of the material in its initial state, but its wear decreased by three-four times. Furthermore, hardly any wear products have been observed during the friction process, which may be very important for application of PTFE in so-called pure technologies, e.g., in the production of semi-conductors [22].

Current research is focused on irradiation of pure polytetrafluoroethylene with gamma rays due to the availability of this type of source, while sources enabling electron radiation with sufficient energy to penetrate the material to a depth of few $\mathrm{cm}$ are less common [20]. In the previous paper by these authors [23,24], results similar to Khatipov's team data were obtained for a high-energy beam of electrons at room temperature. The aim of this study was to investigate the result of an increase in graphite content to $20 \%$ and radiation with a $10 \mathrm{MeV}$ electron beam energy on mechanical, sclerometic and tribological properties of modified PTFE. The possibility of improving in this manner the properties of polymer at ambient temperature would decrease costs related to polytetrafluoroethylene modifications.

\section{Materials and Methods}

The research material was polytetrafluoroethylene with $15 \%$ and $20 \%$ graphite filling (SM-G15 and SM-G20, Inbras, Tarnów, Poland). The rods were made by sintering from PTFE suspension grounded and granulated. The additive used was electrographite with a maximum grain size of $63 \mu \mathrm{m}$, a minimum carbon content of $95 \%$, including $80 \%$ in the graphite structure. Test specimens were cut out in the form of pins with a diameter of $5 \mathrm{~mm}$ (tribological tests) and cylinders with a diameter of $20 \mathrm{~mm}$ (other tests). The finished material was subjected to irradiation with an electron beam on an accelerator with an energy of $10 \mathrm{MeV}$ and a power of $10 \mathrm{~kW}$ (NPO Torij, Moscow, Russia). Dosages from 26-156 kGy (2.6-15.6 Mrad) were used. The process was carried out at room temperature in a vacuum. Then the samples were annealed at $200{ }^{\circ} \mathrm{C}$ for $4 \mathrm{~h}$ and slowly cooled to room temperature.

\subsection{Examination of Thermal Properties of PTFE-Graphite Composites}

The degree of crystallinity of the tested composites was determined by differential scanning calorimetry (DSC) on a Mettler-Toledo DSC 1 device (Mettler-Toledo GmbH, Greifensee, Switzerland). Samples were about $0.015 \mathrm{~g}$ and they were cut from the central part of the cylinder and sealed in 
aluminum cells. The heating rate was $0.167^{\circ} \mathrm{C} / \mathrm{S}$. Thermograms were registered for the melting process at temperatures from -40 to $400{ }^{\circ} \mathrm{C}$, and for the recrystallization process from $400{ }^{\circ} \mathrm{C}$ to $-40{ }^{\circ} \mathrm{C}$. Registered data allowed to determine the degree of crystallinity $\chi_{\mathrm{c}}$, using Formula (1) [25]. The tests were carried out on polymers in the initial state and after exposure to an electron beam.

$$
\chi_{\mathrm{c}}=\frac{\Delta \mathrm{H}_{\mathrm{c}}}{\Delta \mathrm{H}_{\mathrm{f}}} \cdot 100[\%]
$$

where: $\Delta \mathrm{H}_{\mathrm{c}}$-heat of phase transition from a DSC thermogram [cal/g]; $\Delta \mathrm{H}_{\mathrm{f}}$-heat of crystal phase transition of PTFE $(19,585 \mathrm{cal} / \mathrm{g})$.

The heat $\Delta \mathrm{H}_{\mathrm{c}}$, using Formula (2), allows one to calculate the number average molecular weight $\mathrm{M}_{\mathrm{n}}$ of polytetrafluoroethylene-graphite composites [26]:

$$
\mathrm{M}_{\mathrm{n}}=2.1 \cdot 10^{10} \cdot \Delta \mathrm{H}_{\mathrm{c}}^{-5.16}
$$

\subsection{Compressive Strength Tests of PTFE-Graphite Composites}

Uniaxial compression of polytetrafluoroethylene composites with $15 \%$ and $20 \%$ graphite content was performed on Instron 5982, with a constant deformation rate of $4.2 \times 10^{-3} \mathrm{~s}^{-1}$. The deformation was performed up to half the height of the samples, then the system was unloaded without supporting and the maximum stress was determined $\sigma_{\max }=\mathrm{P}_{\max } / \mathrm{A}_{0}$, where $\mathrm{A}_{0}$ is the area of the initial cross-section of the tested samples, and $\mathrm{P}_{\max }$ is the maximum force recorded at $50 \%$ compression. The measurements were performed at a temperature of $21 \pm 1^{\circ} \mathrm{C}$, for each tested variant 5 repetitions were performed.

\subsection{Tests of Micromechanical Properties}

Microindentation tests were performed on a Micron-Gamma device (manufactured by the Aviation Faculty, Technical University of Kiev, Kiev, Ukraine). For measurements, a Berkovich indenter with a pyramid shape and an angle between the center line and each wall equal to $65.3^{\circ}$ was used. Measurement parameters were as follows: maximum load $-1 \mathrm{~N}$ and holding time $-15 \mathrm{~s}$. A load-unload curve was recorded in real time, which allows the determination using the Oliver-Phare method [27], instrumental hardness $\mathrm{H}$, instrumental Young E module, and allowed analysis of the work of indentation (total deformation $-W_{\text {tot }}$, plastic deformation $-W_{\mathrm{pl}}$, and elastic deformation $-W_{\mathrm{sp}}$ ). Six impressions were made for all variants. A self-leveling table was used to increase the accuracy of measurements.

\subsection{Surface Scratch Tests}

The scratches were made using the Revetest device (Anton-Paar, Graz, Austria). A Berkovich indenter with a diameter of $200 \mu \mathrm{m}$ was used in this study. The scratch test parameters were as follows: maximum load $4 \mathrm{~N}$, crack length $4 \mathrm{~mm}$, scratch speed $5.4 \mathrm{~mm} \cdot \mathrm{min}^{-1}$. Three scratches were made for each the tested variants. The profilographic measurements allowed to determine the surface of the groove and elevation $\left(A_{i}\right.$ and $\left.B_{i}\right)$ and on their basis calculate the coefficient of wear mechanism $\beta$ and the wear resistance coefficient $W_{\beta}$ [28-31]:

$$
\mathrm{W}_{\beta}=\frac{1}{\frac{1}{\mathrm{n}} \Sigma_{\mathrm{i}=1}^{\mathrm{n}}\left(\beta_{\mathrm{i}} \mathrm{A}_{\mathrm{i}}\right)}\left[\mathrm{mm}^{-2}\right]
$$

where:

$$
\beta_{i}=\frac{1}{n} \sum_{i=1}^{n} \frac{A_{i}-B_{i}}{A_{i}}
$$




\subsection{Polytetrafluoroethylene-Graphite Composite Wear Tests}

Tribological studies of polymers were carried out using a T-01 tribometer (manufactured by ITeE Radom, Poland). Polytetrafluoroethylene composites with $15 \%$ and $20 \%$ graphite content were tested both at the initial state and after electron beam irradiation. Three pins were prepared. The tests were performed in a pin-on-disk configuration. AISI 321 acid resistant steel (1H18N9T) and titanium grade 2 were used as discs. The surfaces of the discs were ground on 360-1200 grades to obtain a uniform surface roughness of $\mathrm{Ra}=0.2 \mu \mathrm{m}$. This treatment was performed deliberately to allow faster formation of a thin film from the tested composites during the friction process, limiting the coefficient of friction. Tribological test conditions were: load $20 \mathrm{~N}(1 \mathrm{MPa})$, slip speed $10 \mathrm{~cm} / \mathrm{s}$, friction path $1 \mathrm{~km}$, friction path diameter $2.4 \mathrm{~cm}$. Ambient conditions in accordance with VAMAS (Versailles Project on Advanced Materials and Standards) guidelines and ASTM G-99 standard (Standard Test Method for Wear Testing with a Pin-on-Disk Apparatus) [32]. Stereometric analysis of wear traces on the pins was made using a profilograph, and then the surfaces were visualized in 3D using Talymap and Matlab software.

\section{Results and Discussion}

\subsection{Thermal Studies}

It has been determined based on DSC runs that electron-beam irradiation of PTFE with a $15 \%$ and $20 \%$ graphite additive induced a change in thermal properties of composites (Figure 1, please find the original data in Supplementary Materials). The calculations were made on the basis of peaks shown on DSC scans illustrating the melting enanthropicity and crystallization of polyterafluoroethylene and graphite composites. On DSC scans recorded for polytetrafluoroethylene, two main peaks can be seen: the first at a temperature of about $10-40{ }^{\circ} \mathrm{C}$ and the second at a temperature of $320-340{ }^{\circ} \mathrm{C}$. The first is related to crystal form transitions (they are most probably attributable to triclinic/hexagonal and hexagonal/pseudo-hexagonal transitions of the crystalline part of the polymer). The other is related to polymer melting. Irradiation with electron flux affected both changes in molecular weight and degree of crystallinity. The results are shown in Figures 1-5.

First of all, it is clear that for a polymer with higher graphite content the heat of crystallization $\Delta \mathrm{H}_{\mathrm{c}}$ was approximately $20 \%$ lower in the initial state than for a composite with $15 \%$ graphite content (Figure 2). Electron beam irradiation gradually increases $\Delta \mathrm{H}_{\mathrm{c}}$ for both of the examined composites. The heat of crystallization did not change significantly with increase of the dose absorbed by the composites above $52 \mathrm{kGy}$.

As it results from Formula (2), the polymer composites' heat of crystallization is closely related to their molecular weight $\mathrm{M}_{\mathrm{n}}$ (Figure 3). The reduction in molecular weight observed for both PTFE composites with $15 \%$ and $20 \%$ graphite content along with the increase in the absorbed dose of electron beam is influenced by the PTFE chain disruption reactions. A polymer with higher graphite content is characterized by significantly higher average molecular weight in its initial state and, consequently, a more intensive decrease in $\mathrm{M}_{\mathrm{n}}$ after electron beam irradiation.

A significant increase in the crystallinity degree of PTFE with $15 \%$ and $20 \%$ graphite as a function of electron beam irradiation is shown in Figure 4. As mentioned above, when PTFE-graphite composites absorb high doses of radiation, the molecular weight decreases due to the process of chain splitting [33]. It induces due to greater mobility and lower entanglement between polymer particles, which are much more favorable conditions for the formation of new crystallites. The authors of the papers reached similar conclusions [19,34].

With increasing absorbed radiation dose, a linear increase in melting point $\mathrm{T}_{\mathrm{m}}$ of PTFE was observed for both graphite content variants (Figure 5). Furthermore, a polymer with $20 \%$ graphite content was characterized by lower temperature $\mathrm{T}_{\mathrm{m}}$ in its initial condition and higher intensity of growth after electron beam irradiation. Authors of paper [34], who examined PTFE with no additives, obtained similar results after irradiating the polymer with an electron beam of energy of $1.5 \mathrm{MeV}$ and 10 kGy doses. 


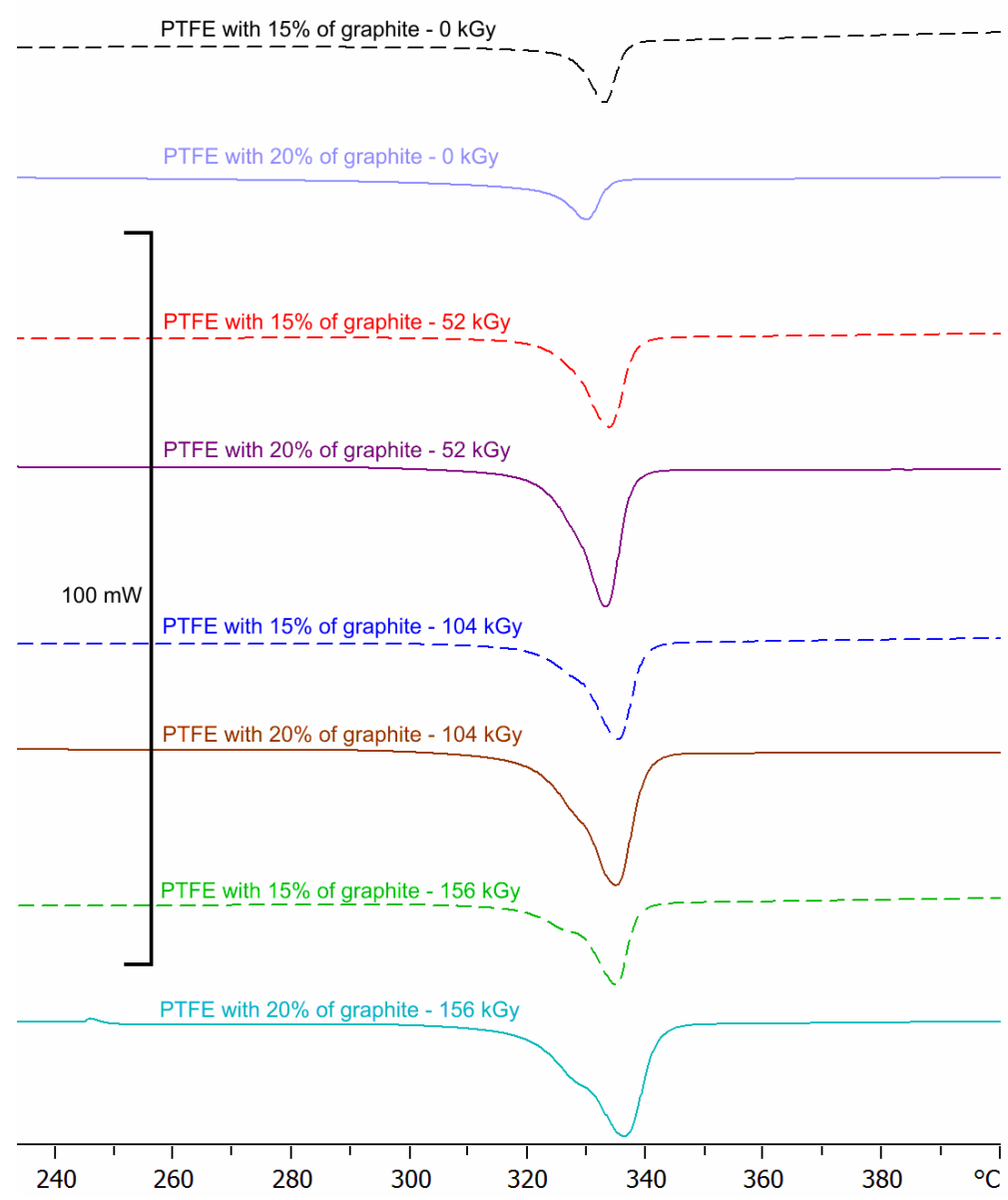

Figure 1. Differential scanning calorimetry (DSC) thermograms of polytetrafluoroethylene (PTFE) with $15 \%$ and $20 \%$ graphite addition.

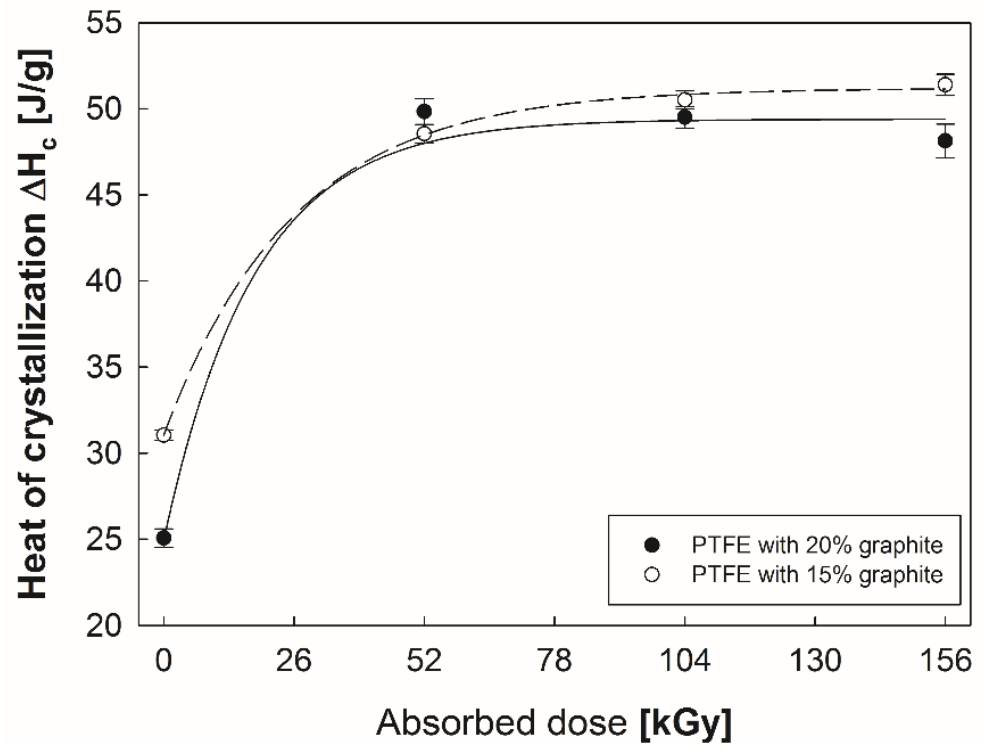

Figure 2. Changes in the crystallization enthalpy of PTFE with $15 \%$ and $20 \%$ graphite addition. 


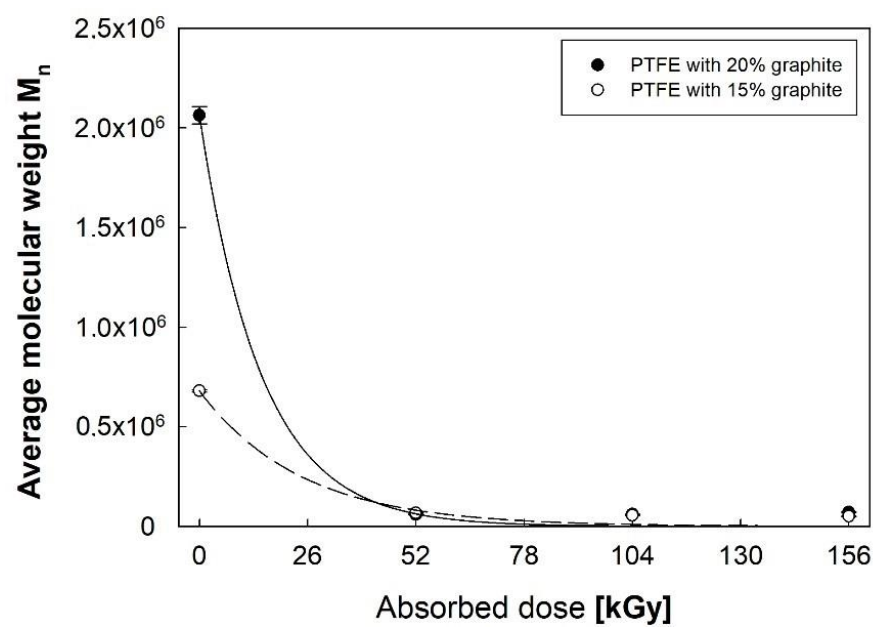

Figure 3. Changes in the average molecular weight of PTFE with different graphite additions.

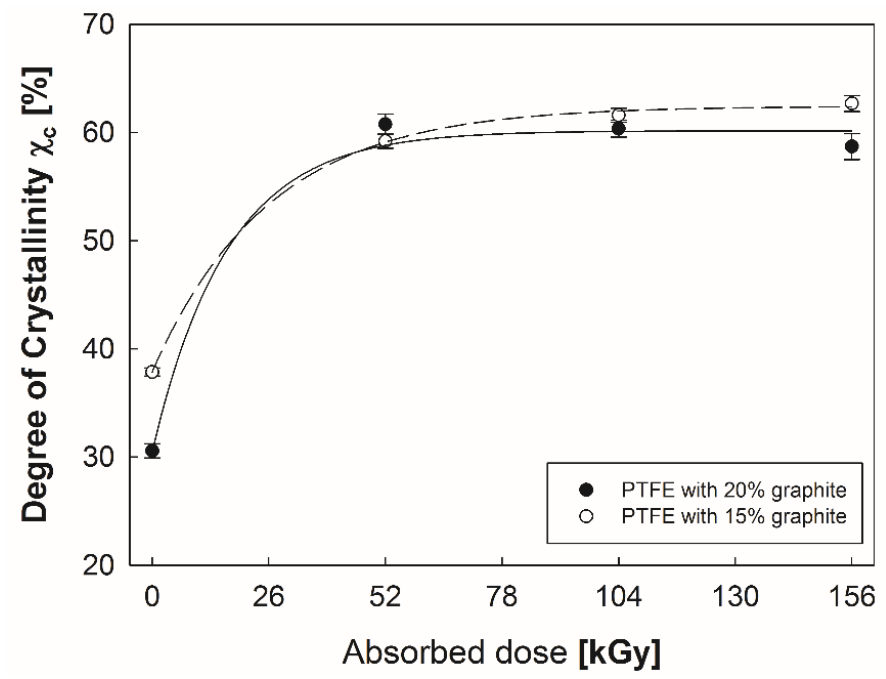

Figure 4. Changes in the crystallinity of PTFE with $15 \%$ and $20 \%$ graphite addition.

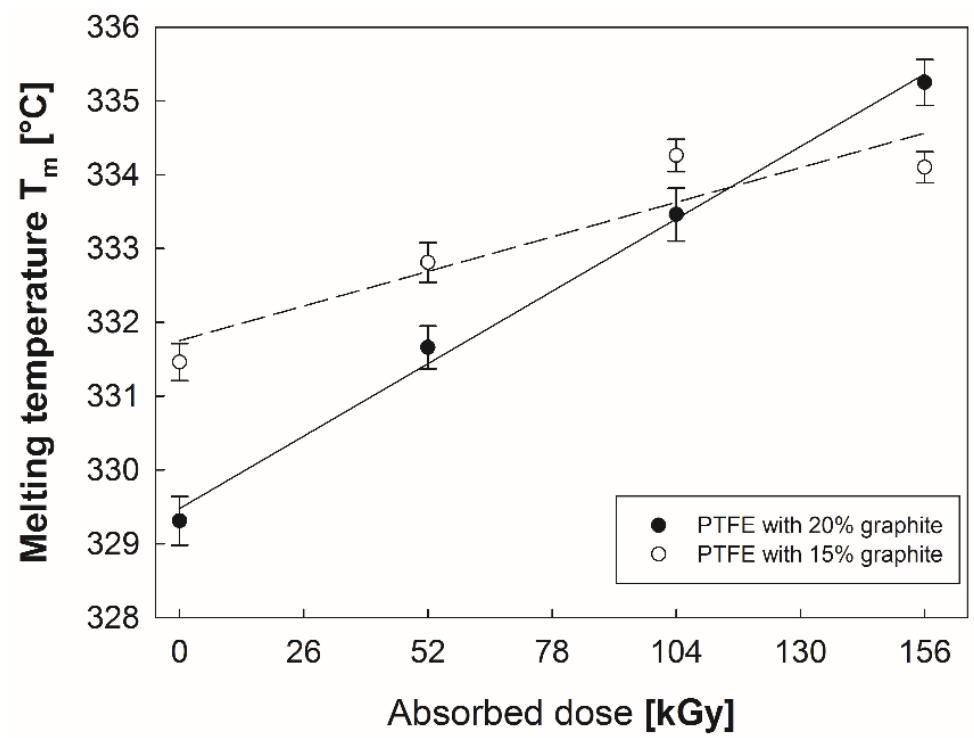

Figure 5. Changes in the melting point temperature of PTFE with $15 \%$ and $20 \%$ graphite addition. 
On this basis, it can be assumed that the effect of electron beam irradiation on thermal properties will have a direct influence on PTFE's mechanical properties and wear resistance of both polymers' (PTFE with 15\% C and PTFE with 20\% C).

\subsection{Mechanical Properties of PTFE}

In spite of a lack of large differences in thermal properties for both of the examined composites subjected to irradiation, significant differences are noticeable in mechanical properties of PTFE with $20 \%$ carbon content compared to PTFE with 15\% C. Electron beam irradiation of both examined composites causes changes in hardness $H$ and Young's modulus $E$, which increase proportionately to the absorbed radiation dose (Figure 6a,b). Changes in the hardness and Young's modulus of PTFE are the consequence of the increase in the crystallinity. It was also found that a polymer with higher graphite content was characterized by $15-25 \%$ higher hardness compared to PTFE with a $15 \%$ graphite additive. As far as Young's modulus is considered, differences between the composites are minor. However, greater increase in the elasticity modules can be observed due to the effect of the electron beam on a polymer with $20 \%$ graphite content. Both parameters $(H, E)$ were subject to a considerable increase, especially in the range of 52-156 kGy, as irradiation i-multiplicity increased.
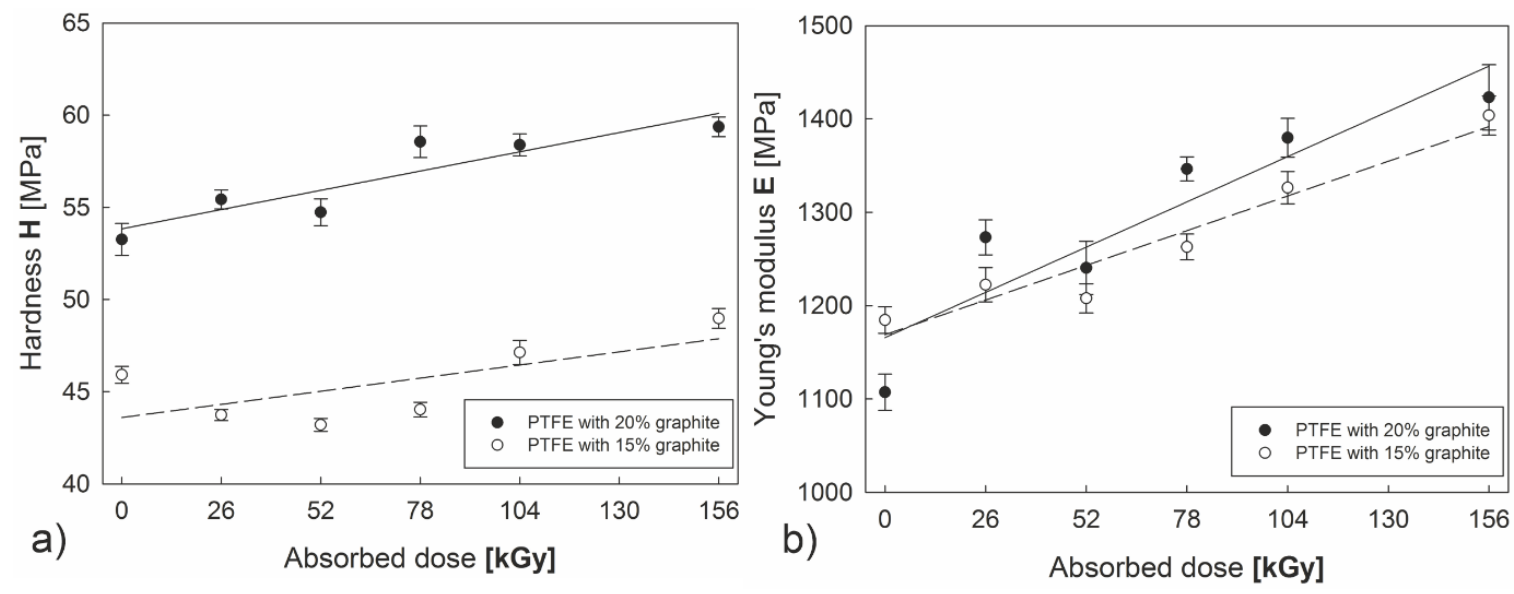

Figure 6. Impact of electron beam irradiation on changes in microhardness $\mathrm{H}$ (a) and modulus of elasticity E (b) of PTFE-graphite composites.

The course of load-unload curves, especially the analysis of the area under the curve allows to determine the parameters of the indentation work. The material's resistance to deformation affects the value of the indentation work determined by the depth, volume and surface of the impressions. The total indentation work $\mathrm{W}_{\text {tot }}$ is the sum of the plastic deformation works $\mathrm{W}_{\mathrm{pl}}$ and the elastic deformation. The area calculations were made using Matlab software.

The performed tests have shown (Figure $7 \mathrm{a}-\mathrm{c}$ ) that introducing additional graphite content reduces the value of total work of indentation. Further decrease in $W_{\text {tot }}$ is observed as the electron beam irradiation dose absorbed by both of the examined polymers increases. Similar dependences occur in the case of work of plastic $\left(\mathrm{W}_{\mathrm{pl}}\right)$ and elastic deformation $\left(\mathrm{W}_{\mathrm{el}}\right)$, which reflects hardness increasing along with the growing radiation dose. Furthermore, lower susceptibility to plastic deformation (Figure $7 \mathrm{~b}$ ) and superior elastic properties (Figure 7c) can be observed in the case of a composite with higher graphite content than in PTFE with $15 \%$ graphite content. 


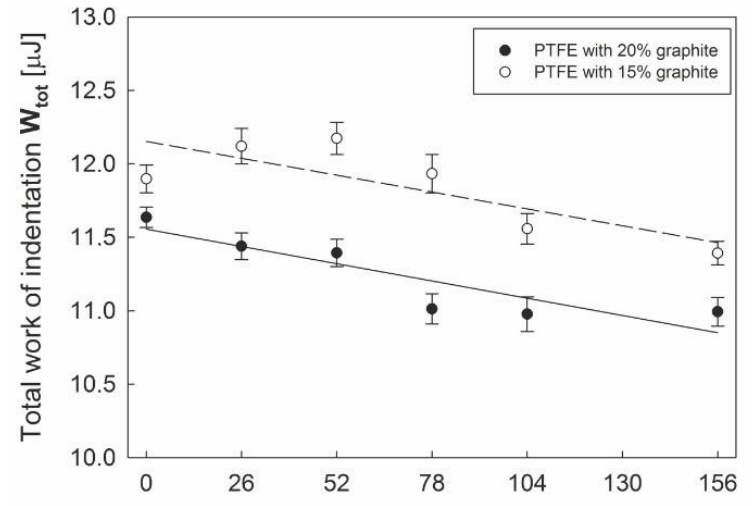

a)

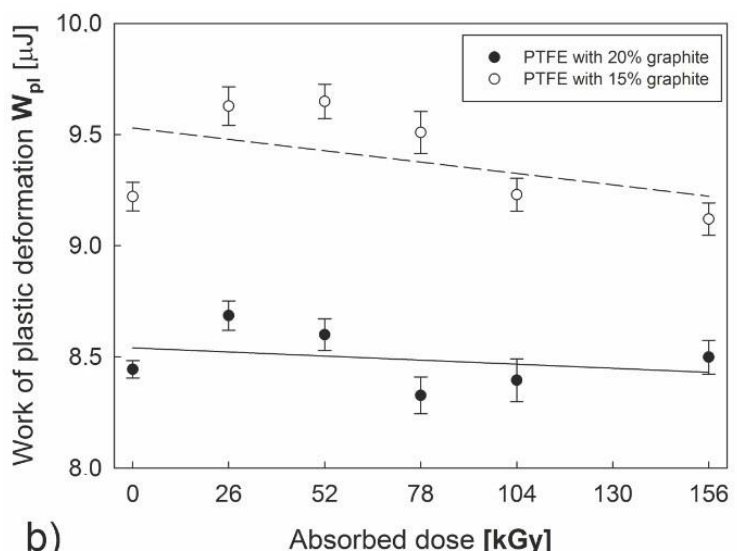

b)

Absorbed dose [kGy]

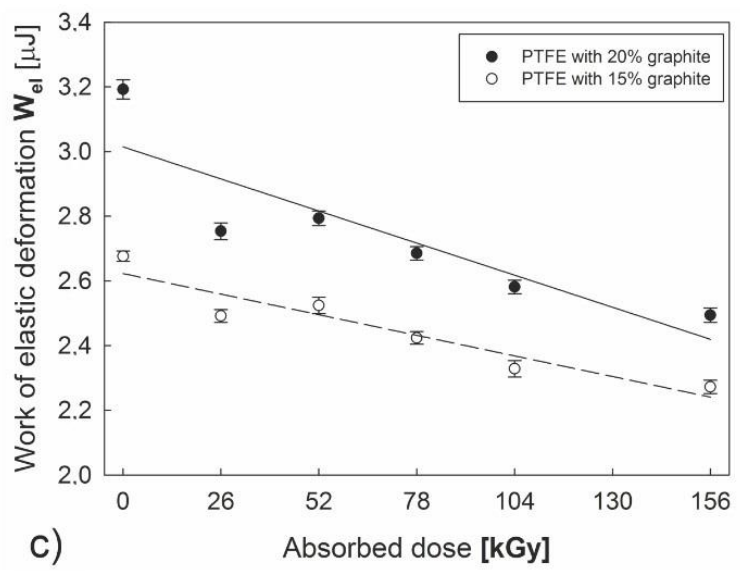

Figure 7. Changes in the work of indentation of PTFE with different graphite additions subjected to an absorbed dose of electron beam irradiation: the total work of indentation- $W_{\text {tot }}(\mathbf{a})$, the work of plastic deformation $-\mathrm{W}_{\mathrm{pl}}(\mathbf{b})$, and the work of elastic recovery $\mathrm{W}_{\mathrm{el}}(\mathbf{c})$.

Differences in graphite content also directly influence PTFE's compression strength $R_{c}$ (Figure 8). Polytetrafluoroethylene with 20\% graphite content was characterized $25 \%-35 \%$ higher strength than PTFE with $15 \% \mathrm{C}$. Electron beam irradiation causes intensive growth of $R_{c}$ of both of the examined composites up to the size of the absorbed dose (104 kGy); absorption of a dose higher than $104 \mathrm{kGy}$ caused deterioration of mechanical properties of the composites. At a high radiation dose (>104 kGy), strength of a polymer decreases due to chain scission in the presence of air, consequently, $R_{c}$ decreases as the radiation dose increases. This may also be caused by the occurrence of radiation-induced oxidation on the surface of the polymers in the presence of air [35]. During irradiation at high doses the oxide layer diffuses into the bulk of the polymer and reduces mechanical properties.

\subsection{The Influence the Addition of Graphite and Irradiation on the Scratch Test Parameters of PTFE}

Stereometric analysis of scratch traces provide information on wear mechanism $\beta$ and resistance to wear $W_{\beta}$ of both of the examined polymers. According to the obtained data (Figure 9a), polytetrafluoroethylene with $20 \%$ carbon content is subject to the machining mechanism to a lesser degree than PTFE with 15\% C after electron beam irradiation. This means that a larger part of the furrow material undergoes plastic deformation during the scratch test and is elevated on the edge of the scratch formed. The most advantageous results for both examined composites were obtained for the absorbed dose of $104 \mathrm{kGy}$. This was corroborated by an increase in wear resistance coefficient $\mathrm{W}_{\beta}$ (Figure 9b), which causes a significant reduction in tribological wear compared to the initial material. Coefficient $W_{\beta}$ increases intensively, especially in the 26-104 kGy range. However, a dose of $156 \mathrm{kGy}$ causes an intensive reduction in this parameter, confirming the fact that high radiation doses lead to degradation of the plastic. 


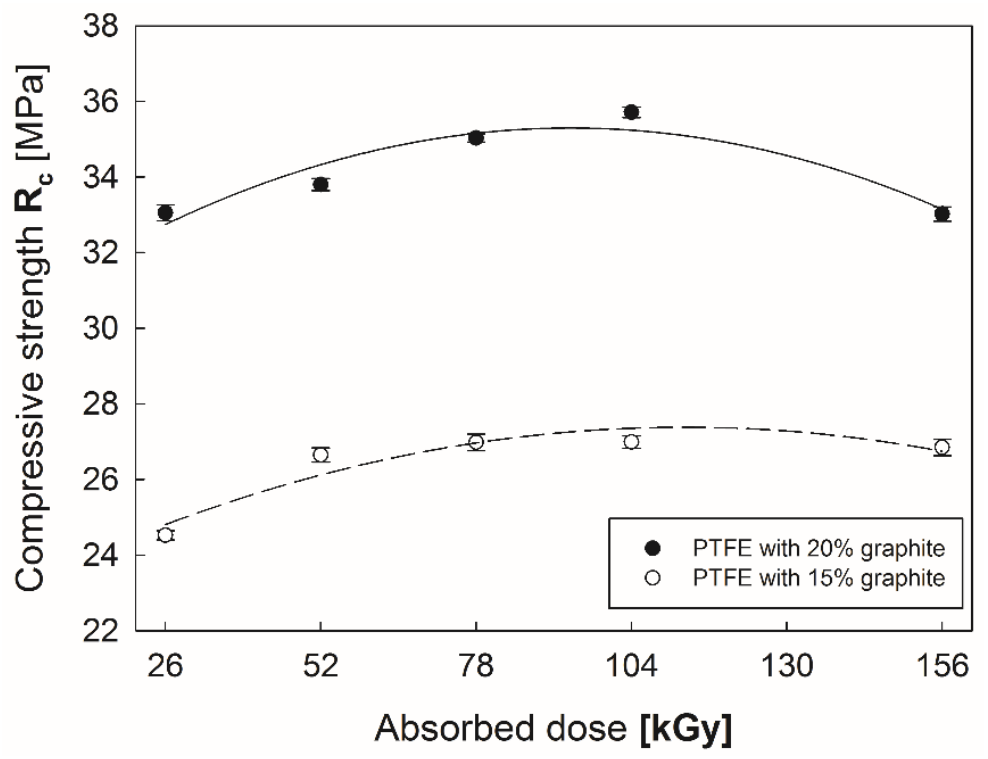

Figure 8. Compressive strength of PTFE with 15\% and 20\% graphite addition. subjected to an absorbed dose of electron beam irradiation.

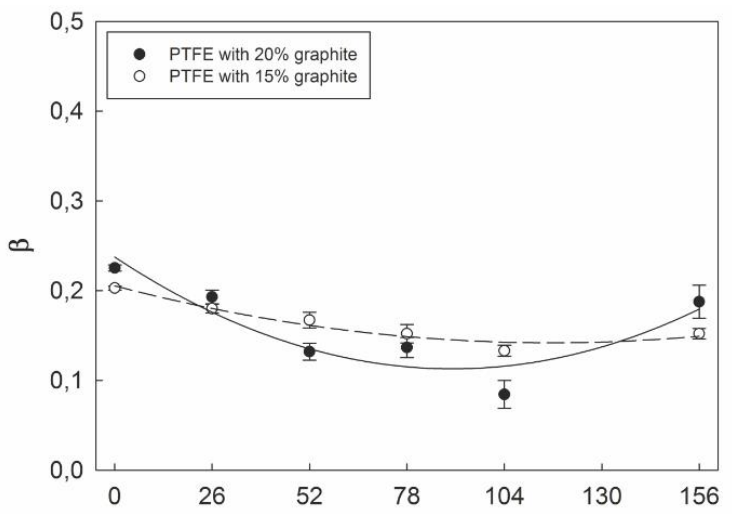

a)

Absorbed dose [kGy]

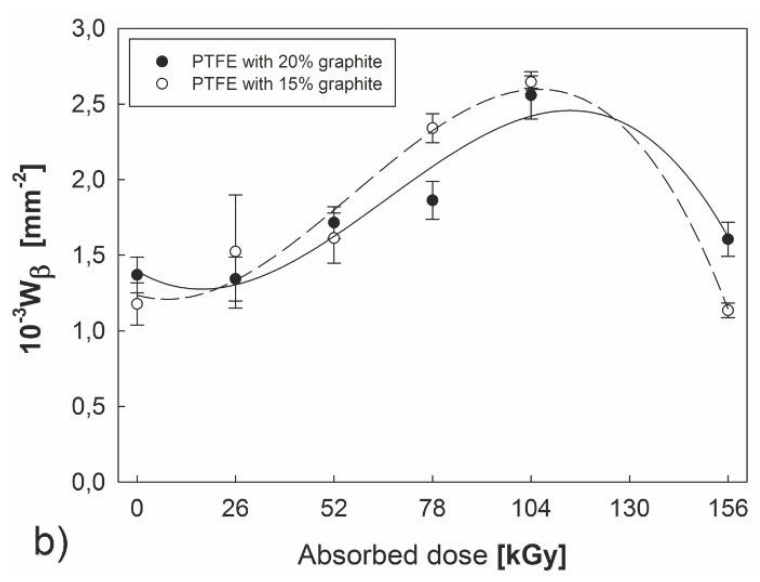

b)

Figure 9. The effect of an absorbed dose of electron beam irradiation dose on the coefficient of the micromechanism of PTFE abrasive wear- $\beta$ (a) and the abrasive wear coefficient $-W_{\beta}(\mathbf{b})$.

\subsection{Wear Properties of PTFE}

The reduction in tribological wear is the most important effect of radiation modification from the point of view of commercial applications of the examined composites. Figure 10 shows linear wear $W_{L}$ PTFE with a $15 \%$ and $20 \%$ graphite additive as a function of the absorbed irradiation dose. It is clear that already in the initial state an increase in graphite content causes a reduction in linear wear both in the case of interaction with 1H18N9T steel (by 25\%) and grade 2 titanium (by 15\%). Electron beam irradiation further reduces wear of both of the examined composites. The most advantageous results were obtained for polytetrafluoroethylene with $20 \%$ graphite content after absorbing a dose of $104 \mathrm{kGy}$. When steel was used as a counterpartner, the reduction in linear wear compared to the initial state was almost four-fold and more than five-fold when compared to a polymer with $15 \%$ graphite content, also in its initial state. A 2.5 fold wear reduction was observed, respectively, in the case of tribological interaction with titanium. Irradiation above a dose of $104 \mathrm{kGy}$ led to polymer degradation. This effect was also visible during tribological tests. $W_{L}$, increased again for a dose of $156 \mathrm{kGy}$, especially for PTFE with $20 \%$ graphite content. 

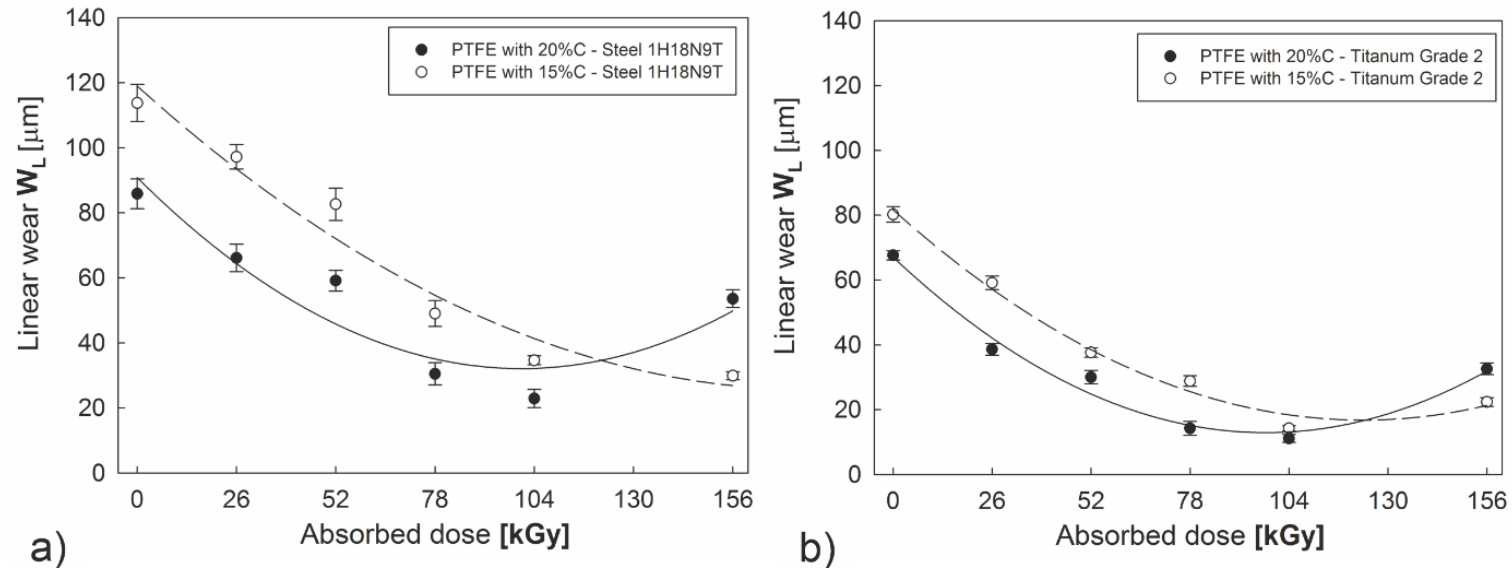

Figure 10. Linear wear of PTFE-graphite composites in combination with discs made of steel (a) and titanium grade $2(\mathbf{b})$ as a function of electron beam irradiation.

Stereometric tests of the friction surface performed with a profilographometer after tribological tests confirmed the reduction in wear. Convexities and concavities, arranged as bands oriented along the motion direction, were found on the friction surface of both examined composites. During the interaction the surface becomes smooth, which smoothness increased with a higher irradiation dose, up to $104 \mathrm{kGy}$ (Figure 11). Such surface morphology indicates the occurrence of lower plastic deformation as well as reduced transport of the surface material during the tribological process. Polymer degradation which occurs when applying higher radiation doses causes friction properties of PTFE to deteriorate.

PTFE with $20 \%$ C - 0 kGy

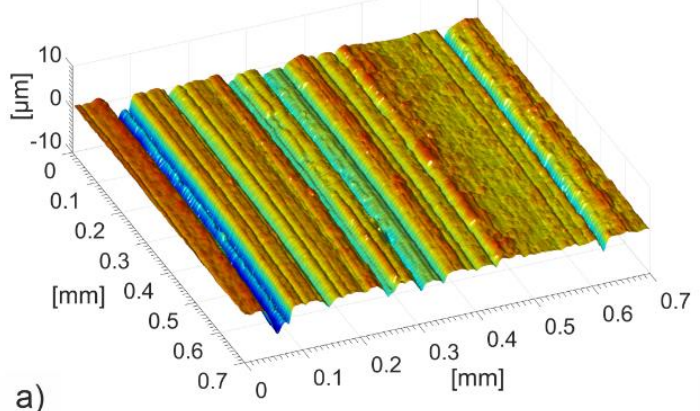

PTFE with $20 \% \mathrm{C}-104 \mathrm{kGy}$

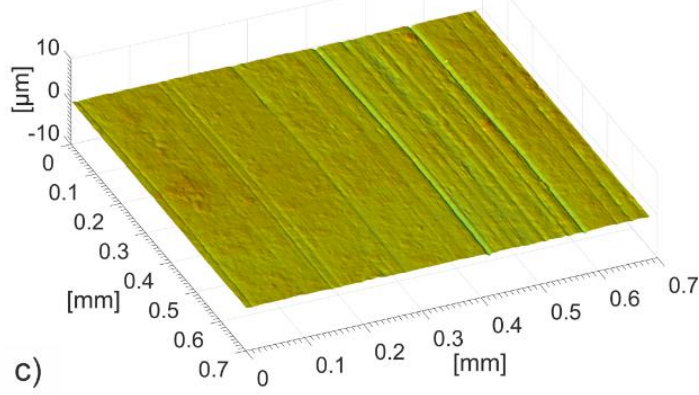

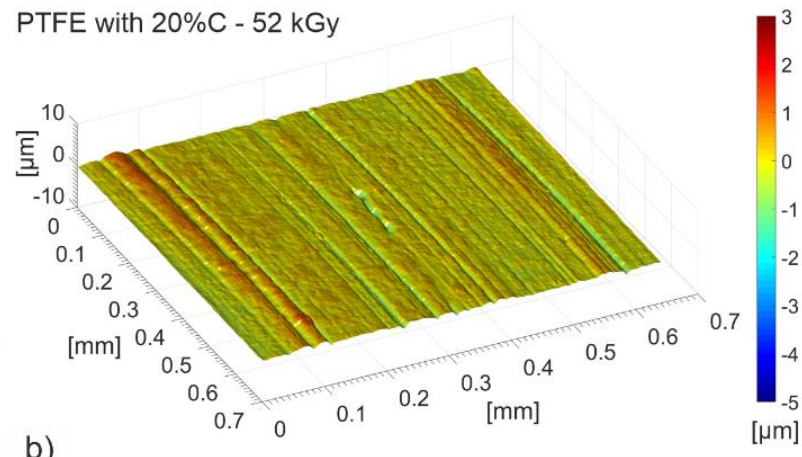

b)

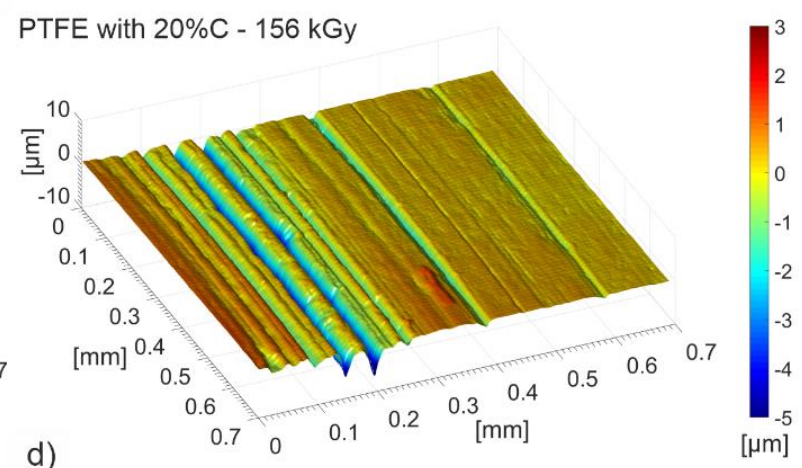

Figure 11. Stereometric structure of the friction surface of PTFE with a $20 \%$ graphite addition in its initial state $0 \mathrm{kGy}$ (a) and after absorbing a dose of $52 \mathrm{kGy}(\mathbf{b}), 104 \mathrm{kGy}(\mathbf{c}), 156 \mathrm{kGy}$ (d). 


\section{Conclusions}

1. Electron beam irradiation gradually increased crystallization heat $\Delta \mathrm{H}_{\mathrm{c}}$ for both examined composites. The PTFE with higher graphite content was characterized by $20 \%$ lower value of $\Delta \mathrm{H}_{\mathrm{c}}$ compared to PTFE $+15 \% \mathrm{C}$ in the initial state. These studies also showed that along with the pattern of absorbed radiation dose and progressive chain cleavage reactions of both PTFE-graphite composites, there is a decrease in the molecular weight of polymers.

2. PTFE with 15 and $20 \%$ graphite content is characterized by a higher degree of crystallinity after irradiation. This is the result of changes in molecular weight and changes in the length of polymer chains after irradiation, which facilitates the crystallization process. The decreasing tendency of molecular weight of PTFE with the increasing dose of absorbed electron beam irradiation has also been shown, which can be attributed to the chain scission reaction of PTFE under increased doses.

3. An increase in graphite content to $20 \%$ and an increase in crystallinity contributes to an increase in the compressive strength, modulus of elasticity and microhardness determined by means of microindentation. Introducing an additional quantity of graphite reduced the value of the total work of indentation Wtot and improved elastic properties of the composite.

4. A decrease in susceptibility to deformation, a change in the micromechanism of wear $\beta$ towards the furrow and an increase in wear resistance represented by the $W_{\beta}$ coefficient was demonstrated by surface scratch tests, and their increase was affected by a change in the graphite content to $20 \%$ in the tested composites and electron beam irradiation.

5. An increase in graphite content to $20 \%$ in the initial state caused a reduction in linear wear during interaction with both steel and titanium. Electron beam irradiation further reduced wear of both examined composites. The most advantageous results were obtained for polytetrafluoroethylene with $20 \%$ graphite content after absorbing a dose of $104 \mathrm{kGy}$. With steel as a counterpartner, the reduction in linear wear compared to the initial state was almost four-fold and more than five-fold when compared to a polymer with $15 \%$ graphite content. Profilographometric tests have shown that during the interaction the surface of polymers becomes smooth as the irradiation dose increases. This reduces transport of the material from the surface, which is a desirable phenomenon in tribological applications, especially in systems which do not require lubrication.

6. Irradiation of PTFE with a dose of $156 \mathrm{kGy}$ causes its degradation which manifests itself through degraded mechanical properties and an increase in the linear wear of both of the examined composites.

7. Modification of PTFE through its irradiation with an electron beam may contribute to extending the life cycle of this material, e.g., in sliding components which work under heavy load conditions.

Supplementary Materials: The following are available online at http://www.mdpi.com/2073-4360/12/8/1676/s1, the original data of stress stain curves of PTFE with a $15 \%$ and $20 \%$ graphite addition.

Author Contributions: Conceptualization, A.B. and A.S.S.; methodology, A.B., K.A., A.S.S., and S.K.; software, A.B., A.S.S., and S.K.; validation, J.G. and A.S.; formal analysis, A.B., A.S.S., S.K., A.S., and J.G.; investigation, A.B., K.A., J.G., and S.K.; resources, A.B. and J.G.; data curation, K.A. and J.G.; writing-original draft preparation, A.B., A.S.S., K.A., and S.K.; writing-review and editing, A.S., Z.W., and B.K.; visualization, A.S.S. and A.S.; supervision, A.B., A.S.S., A.S., Z.W., and B.K.; project administration, A.B. and A.S.S.; funding acquisition, A.S.S. All authors have read and agree to the published version of the manuscript.

Funding: This research received no external funding.

Conflicts of Interest: The authors declare no conflict of interest.

\section{References}

1. Cox, J.M.; Wright, B.A.; Wright, W.W. Thermal degradation of fluorine-containing polymers. Part I. Degradation in vacuum. J. Appl. Polym. Sci. 1964, 8, 2935-2950. [CrossRef]

2. Bruk, M.A. Radiation-thermal crosslinking of polytetrafluoroethylene. High Energy Chem. 2006, 40, 357-369. [CrossRef] 
3. Briscoe, B.J.; Ni, Z. The friction and wear of $\gamma$-irradiated polytetrafluoroethylene. Wear 1984, 100, $221-242$. [CrossRef]

4. Rossa, B.B. Fluorocarbon polymers in the Chemical Industry. Prakt. Chem. 1964, 15, 64-73.

5. Ehrlich, P.J. Dielectric properties of teflon from room temperature to $314^{\circ} \mathrm{C}$ and from frequencies of $10^{2}$ to $10^{5} \mathrm{c} / \mathrm{s}^{1}$. J. Res. Nat. Bur. Stand. 1953, 51, 185-188. [CrossRef]

6. Singh, S.; Tyagi, M.; Seshadri, G.; Tyagi, A.K.; Varshney, L. Effect of gamma radiation on graphite-PTFE dry lubrication system. Radiat. Phys. Chem. 2017, 141, 213-219. [CrossRef]

7. Tanaka, K.; Uchiyama, Y.; Toyooka, S. The mechanism of wear of polytetrafluoroethylene. Wear 1973, 23, 153-172. [CrossRef]

8. Steijn, R.P. The sliding surface of polytetrafluoroethylene: An investigation with the electron microscope. Wear 1968, 12, 193-212. [CrossRef]

9. Kajdas, C.; Harvey, S.S.K.; Wilusz, E. Encyclopedia of Tribology; Elsevier: Amsterdam, The Netherlands, 1990; ISBN 9780080875798.

10. Wheeler, D.R. The transfer of polytetrafluoroethylene studied by X-ray photoelectron spectroscopy. Wear 1981, 66, 355-365. [CrossRef]

11. Blanchet, T.A.; Kennedy, F.E. Sliding wear mechanism of polytetrafluoroethylene (PTFE) and PTFE composites. Wear 1992, 153, 229-243. [CrossRef]

12. Blanchet, T.A.; Peng, Y.L.; Nablo, S.V. Tribology of selectively irradiated PTFE surfaces. Tribol. Lett. 1998, 4, 87-94. [CrossRef]

13. Charlesby, A. (Ed.) Atomic Radiation and Polymers; Pergamon: Oxford, UK, 1960; ISBN 9781483222790.

14. Chapiro, A. Radiation Chemistry of Polymeric Systems; Interscience Publishers: New York, NY, USA, 1962; ISBN 0470392851.

15. Dole, M. The Radiation Chemistry of Macromolecules; Academic Press: New York, NY, USA, 1972; ISBN 9780323152839.

16. Campbell, F.J. Radiation damage in organic materials. Radiat. Phys. Chem. 1981, 18, 109-123. [CrossRef]

17. Tabata, Y.; Suzuki, H.; Ikeda, S. Radiation modification of PTFE and its application. Radiat. Phys. Chem. 2013, 84, 14-19. [CrossRef]

18. Tang, Z.; Wang, M.; Zhao, Y.; Wu, G. Radiation resistance evaluation of cross-linked polytetrafluoroethylene by the investigation of friction and wear behavior. Radiat. Phys. Chem. 2011, 80, 496-500. [CrossRef]

19. Tang, Z.; Wang, M.; Zhao, Y.; Wu, G. Tribological properties of radiation cross-linked polytetrafluoroethylene sheets. Wear 2010, 269, 485-490. [CrossRef]

20. Menzel, B.; Blanchet, T.A. Enhanced wear resistance of gamma-irradiated PTFE and FEP polymers and the effect of post-irradiation environmental handling. Wear 2005, 258, 935-941. [CrossRef]

21. Khatipov, S.A.; Konova, E.M.; Artamonov, N.A. Radiation-modified polytetrafluoroethylene: Structure and properties. Rus. J. Gen. Chem. 2009, 79, 2006-2015. [CrossRef]

22. Khatipov, S.A.; Sichkar, V.P.; Voronina, E.N.; Ivanchenko, V.K.; Sobolev, G.P.; Bruk, M.A. Method for Thermoradiation Treatment of Polytetrafluoroethylene Products. RU Patent 2,211,228, 27 August 2003.

23. Barylski, A.; Maszybrocka, J.; Kupka, M.; Aniołek, K.; Kaptacz, S. Radiation-chemical modification of PTFE in the presence of graphite. J. Appl. Polym. Sci. 2015, 132, 42348. [CrossRef]

24. Barylski, A.; Aniołek, K.; Swinarew, A.S.; Kaptacz, S.; Gabor, J.; Waśkiewicz, Z.; Stanula, A. Novel Organic Material Induced by Electron Beam Irradiation for Medical Application. Polymers 2020, 12, 306. [CrossRef]

25. Rabek, J.F. Fundamentals of Physical Chemistry of Polymers; Wroclaw University of Technology Publisher: Wroclaw, Poland, 1977.

26. Takeshi, S.; Masaaki, T.; Sueo, M. Melting and crystallization behavior of poly(tetrafluoroethylene). New method for molecular weight measurement of poly(tetrafluoroethylene) using a differential scanning calorimeter. J. Appl. Polym. Sci. 1973, 17, 3253-3257.

27. Oliver, W.C.; Pharr, G.M. An improved technique for determining hardness and elastic modulus using load and displacement sensing indentation experiments. J. Mater. Res. 1992, 7, 1564-1583. [CrossRef]

28. Samborski, T.M. Method of Identifying Stereometric Wear. Ph.D. Thesis, Faculty of Mechanical Engineering, University of Technology, Cracow, Poland, 2002.

29. Cybo, J.; Maszybrocka, J.; Barylski, A.; Kansy, J. Resistance of UHMWPE to plastic deformation and wear and the possibility of its enhancement through modification by radiation. J. Appl. Polym. Sci. 2012, 125, 4188-4196. [CrossRef] 
30. Jardret, V.; Zahouani, H.; Loubet, J.L.; Mathia, T.G. Understanding and Quantification of Elastic and Plastic Deformation during a Scratch Test. Wear 1998, 218, 8-14. [CrossRef]

31. Hokkirigawa, K.; Kato, K. An Experimental and Theoretical Investigation of Ploughing, Cutting and Wedge Formation during Abrasive Wear. Trib. Inter. 1988, 21, 51-57. [CrossRef]

32. Czichos, H.; Becker, S.; Lexow, J. Multilaboratory tribotesting: Results from the VAMAS program on wear test methods. Wear 1987, 114, 109-130. [CrossRef]

33. Chipara, M.D.; Chipara, M.I. Effects of Gamma Radiation on PTFE. Polym. Degrad. Stab. 1992, 37, 67-71. [CrossRef]

34. Karmakar, S.; Lawrence, F.; Mallika, C.; Kamachi Mudali, U. Radiation Degradation of Polytetrafluoroethylene-Lead Composites. J. Mater. Eng. Perf. 2015, 24, 4409-4414. [CrossRef]

35. Abdou, S.M.; Mohamed, R.I. Characterization of structural modifications in poly-tetra-fluoroethylene induced by electron beam irradiation. J. Phys. Chem. Solids 2002, 63, 393-398. [CrossRef]

(C) 2020 by the authors. Licensee MDPI, Basel, Switzerland. This article is an open access article distributed under the terms and conditions of the Creative Commons Attribution (CC BY) license (http://creativecommons.org/licenses/by/4.0/). 